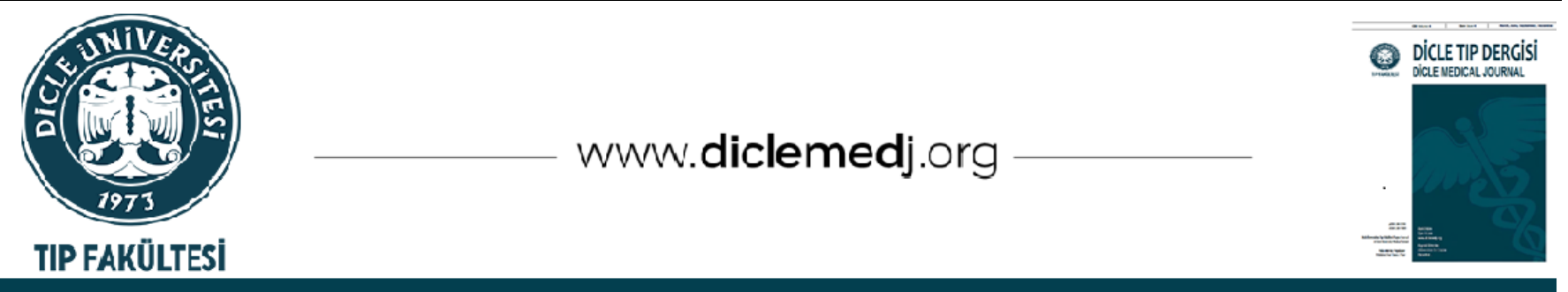

Özgün Araştırma / Original Article

\title{
Tubal Reanastomoz Sonrası Gebelik Sonuçları: Yeni Bir Teknik
}

\author{
Adnan Yener ${ }^{\left(D_{1}\right.}$, Burak Giray ${ }^{\left(D_{2}\right.}$ \\ 1 Kadın Hastalıkları ve Doğum Kliniği, Necip Fazıl Şehir Hastanesi, Kahramanmaraş, Türkiye \\ 2 Kadın Hastalıkları ve Doğum Kliniği, Sancaktepe Şehit Prof. İlhan Varank Eğitim ve Araştırma Hastanesi, İstanbul, Türkiye \\ Geliş: 01.07.2021; Revizyon: 26.10.2021; Kabul Tarihi: 10.11.2021
}

Öz

Amaç: Tubal sterilizasyon sonrası bazı hastalar pişmanlık duyabilir. Bu gibi durumlarda cerrahi yöntemlerle tubal reanastomoz işlemi gerçekleştirilebilir. Çalışmanın amacı tubal reanastomozda yeni bir tekniği tanımlamak ve bu teknik sonrası gebelik sonuçlarını yayınlamaktır.

Yöntemler: Çalışmamıza daha önceden tüp ligasyonu yapılan ve yeni bir yöntemle tubal reanastomoz uygulanan 28 hasta dahil edilmiştir.

Bulgular: Hastaların ortalama yaşı $35,25 \pm 4,08$ idi. Tubal ligasyondan reanastomoza kadar geçen süre 12 ila 76 ay arasında değişmekte olup, ortalama $41,5 \pm 26,3$ ay idi. Tubal reanastomoz sonrası gebelik oranı, canlı doğum oranı ve abortus oranı sırasıyla \%42,9, \%32,1 ve \%10,7 idi. Hiçbir hastada ektopik gebelik gelişmedi. Hastaların 8'i $(\% 28,6)$ ilk 1 yıl içerisinde gebe kaldı. Gebelik oluşmayan tüm hastalara 12 ay sonunda çekilen histerosalpingografide tubal geçişin olduğu izlendi.

Sonuç: Tubal sterilizasyon sonrası gebeliğe engel başka bir problemi olmayan özellikle genç yaştaki kadınlar için tubal reanastomoz işlemi etkin bir yöntemdir.

Anahtar kelimeler: gebelik; tubal reanastomoz; tubal sterilizasyon.

DOI: 10.5798/dicletip.1037826

Yazışma Adresi / Correspondence: Burak Giray, Kadın Hastalıkları ve Doğum Kliniği, Sancaktepe Şehit Prof. İlhan Varank Eğitim ve Araştırma Hastanesi, İstanbul, Türkiye e-mail: burakgiray@gmail.com 


\section{Pregnancy Outcomes After Tubal Reanastomosis: A Novel Technique}

\section{Abstract}

Objective: Some patients may regret after tubal sterilization. In such cases, tubal reanastomosis can be performed by surgical methods. The aim of the study is to describe a new technique in tubal reanastomosis and to report the pregnancy results after this technique.

Methods: Twenty-eight patients who underwent tubal reanastomosis with a new method after tubal sterilization were included in the study.

Results: The mean age of the patients was $35.25 \pm 4.08$ years. The range of the time from tubal ligation to reanastomosis was 12 to 76 months, with a mean of $41.5 \pm 26.3$ months. Overall pregnancy, live birth, and abortion rates after tubal reanastomosis were $42.9 \%, 32.1 \%$, and $10.7 \%$, respectively. There was no ectopic pregnancy. Eight of the patients $(28.6 \%)$ became pregnant within the first year. Hysterosalpingography was performed in patients who did not become pregnant after 12 months, and hysterosalpingography revealed bilateral tubal spillage.

Conclusion: In the absence of other conditions preventing pregnancy, tubal reanastomosis is an effective method for young women who want to become pregnant after tubal sterilization.

Keywords: pregnancy; tubal sterilization; tubal reanastomosis.

\section{GíRİs}

Tubal sterilizasyon yöntemi hem dünya genelinde hem de ülkemizde yaygın olarak kullanılan bir kontrasepsiyon yöntemidir. Özellikle 35 yaşından sonra sık tercih edilen yöntemlerdendir ve etkinliği oldukça yüksektir ${ }^{1}$. Sezaryen oranlarının tüm dünyada artmasiyla birlikte sezaryen sirasinda tüp ligasyonu yapılmasının da bu yöntemin tercih edilmesinde artışa yol açmıştır ${ }^{2}$. Tercih edilmesini sağlayan diğer sebepler ise tek seferlik işlem olması, her gün alınması gereken bir ilaç olmaması ve yüksek koruma oranları sıralanabilir. Yapılan cerrahi işlem sonrası bir grup hasta çeşitli nedenlerle pişmanlık da yaşayabilmektedir. Tubal sterilizasyon sonrası pişmanlı oranı \%1-15 arasında değişmektedir ${ }^{3,4}$. Hastaların ise yaklaşık \%1020 'si tubal reanastomoz talebinde bulunmaktadır ${ }^{4}$. Pişmanlık sebepleri arasında psikolojik sebepler, dini inançlar, yeni bir çocuk istemi, çocuk ölümü ya da yeni bir eşten çocuk istemi gibi faktörler siralanabilir. $\mathrm{Bu}$ gibi durumlarda cerrahi yöntemlerle (laparotomik, laparoskopik ya da robotik) tubal reanastomoz işlemi gerçekleștirilebilir ${ }^{5}$. Tubal reanastomoz sonrası gebelik oranları ise \%31-74 arasında değișkenlik göstermektedir ${ }^{4,6-12}$.

Çalışmamızdaki amaç tubal reanastomozda yeni bir tekniği tanımlamak ve bu teknik sonrası gebelik sonuçlarını yayınlamaktır.

\section{YÖNTEMLER}

Çalışmamıza daha önceden tüp ligasyonu yapılan ancak çeșitli sebeplerle tekrar tüplerinin açılmasını isteyen ve Ocak 2018Ocak 2021 tarihleri arasında söz konusu yöntemle tubal reanastomoz uygulanan 28 hasta dahil edilmiştir. Hastalara ait veriler hastane kayıtlarından, yüz yüze görüşerek ya da telefonla görüşerek elde edilmiştir. Hastaların yaşları, önceki obstetrik öyküsü, sterilizasyon zamanları ve diğer demografik özellikleri kaydedildi. Hastalara tubal reanastomoz yapılmadan önce fertiliteleri değerlendirildi. Hastalardan hormon profili ve eşlerinden de spermiogram istendi. Hastalar detayl bir muayeneyle gebeliğe engel başka durum olup olmadığ 1 kontrol edildi. İşlem öncesi tüm hastalara histerosalfingografi çekilerek uterusun ve tuba uterinaların durumu değerlendirildi (Figür 1). Bütün bu değerlendirmeler sonucunda tubal 
sterilizasyon sebebi dışında gebeliğe engel bir durum olmayan hastalardan sözlü ve yazılı onam alınarak tubal reanastomoz ișlemi uygulandı.

Araştırma için etik kurul komitesinden etik kurul onayı alınmıştır (etik kurul onay tarihi ve numarası: 2021/167).
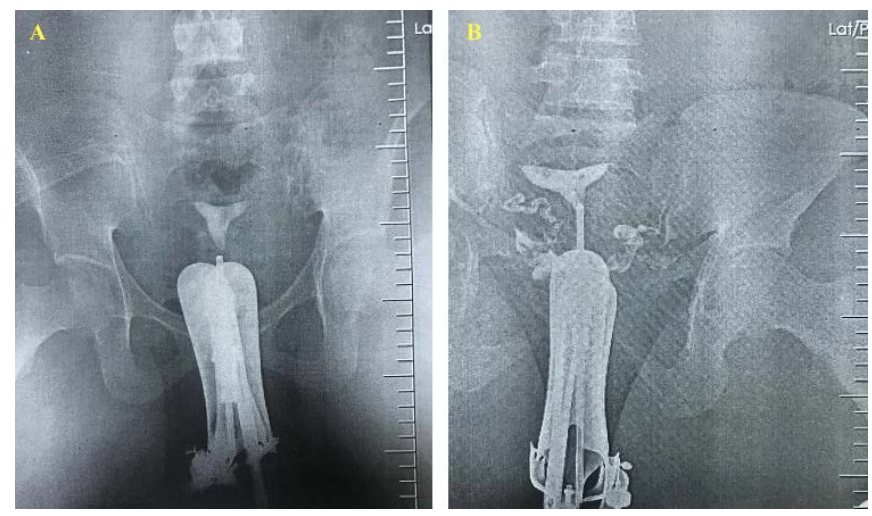

Figür 1: Bilateral tubal reanastomoz uygulanan bir hastanın histerosalpingografi görüntüleri. A) İşlem öncesi, B) İşlemden 3 ay sonra.

\section{Cerrahi teknik}

Hastalar spinal veya genel anestezi altında iken pfannenstiel insizyonla batına girildi. Her iki tuba uterina açığa çıkarıldı. Tuba uterinanın istmik bölgeden kesilen bölgesi tespit edilerek uterusa yakın proksimal kısmı ile fimriyaya yakın distal kısmı yaklaşık 0,5 cm olacak şekilde tekrar kesildi ve tubal pasaj her iki uçta açık hale getirildi. Tubanın distal parçasının fimbriyal ucundan standart epidural kataterin yuvarlatılmış ucuyla girildi (Figür 2). Tubanın kesilmiş olan ucundan çıkılıp tekrar proksimal parçanın distal ucundan girilerek epidural katater uterusun içine 20-30 cm kadar ilerletildi. Kesilmiş olan tubal uçlar 5-0 vicryl sütür ile üç yerden uç uca anastomoz edildi. Daha sonra fimbriyal uçtan çıkan katater batın duvarından dışarı çıkarılıp cilde sütüre edilip sabitlendi. Böylece epidural kataterin bir ucu uterusun içinde diğer ucu ise batın dişında kalmış oldu (Figür 2). Aynı işlem bilateral yapılmasına uygun olan hastalarda diğer tarafa da uygulandı. Batın usulüne uygun kapatıldı.
Tubal anastomozdan 24 saat sonra katater batın ucundan 5-6 cm dışarı çekildi ve devam eden günlerde 48 saat ara ile çekme işlemi tekrarlandı. Postop 8 gün sonra katater batından tamamen çıkarıldı. Hastalar taburcu edildi. Hastalarda 12 ay sonra gebelik oluşmaması halinde tüplerin durumunu değerlendirmek için histerosalpingografi çekildi.

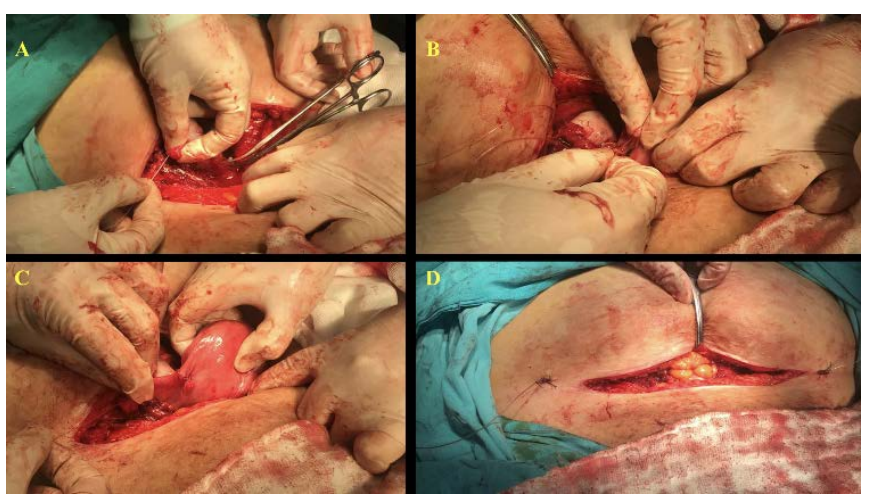

Figür 2: Yapılan tubal reanastomoz tekniğinin etap etap görüntüleri. A) Epidural kataterin fimbrial uçtan sokulması, B) Epidural kataterin tubanın proksimal parçasından sokulup uterusa ilerletilmesi, C) Tuba uterinaya uygulanan anastomoz sütürleri sonrası görüntüsü, D) Cildi kapatmadan hemen önce epidural kataterlerin batın duvarından çıktığı yerlerin görüntüsü.

\section{İstatistiksel analiz}

$\mathrm{Bu}$ çalışmada istatistiksel analizler için SPSS versiyon 26 (The Statistical Package for Social Sciences, Chicago, IL, USA) programı kullanılmıştır. Tanımlayıcı veriler ortalama, standart sapma, sıklık ve yüzde olarak verildi.

\section{BULGULAR}

Hastaların ortalama yaşı 35,25 $\pm 4,08$ idi. Median gravida 3 (2-6), parite 2 (1-4) idi. Hastaların 19 'u daha önceden sezaryen ameliyatı geçirmişti. Ayrıca 9 hasta sezaryene ek olarak apendektomi ameliyatı da geçirmişti. Tubal ligasyondan reanastomoza kadar geçen süre 12 ila 76 ay arasında değişmekte olup, ortalama $41,5 \pm 26,3$ ay idi. Yirmi üç hastaya bilateral tubal reanastomoz işlemi uygulanırken, 5 hastaya unilateral tubal reanastomoz işlemi uygulandı. Hastaların hiçbirinde intraoperatif ya da 
postoperatif komplikasyon gelişmedi. Tubal reanastomoz sonrası toplamda $12 \quad(\% 42,9)$ gebelik oluştu. Toplamda $9(\% 32,1)$ hastada canlı doğum gerçekleşirken, $3(\% 10,7)$ hastada abortus meydana geldi. Hiçbir hastada ektopik gebelik gelişmedi. Hastaların 8'i $(\% 28,6)$ ilk 1 yıl içerisinde gebe kaldı. Gebelik oluşmayan tüm hastalara 12 ay sonunda çekilen histerosalpingografide tubal geçiş olduğu izlendi.

\section{TARTIŞMA}

Kontrasepsiyon yöntemleri arasında tubal sterilizasyon yöntemi en etkin yöntemler arasında yer almasına rağmen sonradan kişinin pişmanlık duyması ya da fikrini değiștirmesi halinde problem teşkil etmektedir. Kişinin tekrar gebe kalmak istemesi hainde ise cerrahi olarak tubal reanastomoz iyi bir alternatiftir. Literatürde tubal reanastomoz sonrası tüplerin açılma oranları tatmin edicidir. Kavoussi ve ark. yaptığı robotik tubal reanastomoz işlemi sonrası tüp açılma oranlarını \%94,1 olarak rapor etmişlerdir 5 . Bizim çalışmamızda da tüm hastalarda işlem sonrası tüplerin açı olduğu görülmüştür. Her ne kadar tüplerin açılma oranları bu kadar yüksek olsa da literatürde tubal reanastomoz sonrası gebelik ve canlı doğum oranları bu kadar yüksek değildir. Berger ve ark. yaptığı bir çalışmada tubal reanastomoz sonrası gebelik oranı \%69 bulunmuş olup, canlı doğum oranı \%35 olarak rapor edilmiştir ${ }^{10}$. Yakın zamanda yapılan bir derlemede 10689 kadının verileri değerlendirilmiş ve gebelik oranları \%42 ile $\% 69$ arasında bulunmuştur ${ }^{13}$. Çalışmamızda ise işlem sonrası gebelik oranı \%42,9, canlı doğum oranı ise \%32,1 olarak bulunmuştur. Laparoskopik tubal ligasyon ile Pomeroy usulü tubal ligasyon sonrası yapılan reanastomozların gebelik oranlarının karşılaştırıldığı bir çalışmada Pomeroy usülü sonrası yapılan tubal reanastomozda gebelik oranı \%16,7 olarak bulunmuştur ${ }^{14}$. Yazarlar bu çalıșmada sterilizasyon sonrası kalan tubal uzunluğun reanastomozda başarıyı etkilediği sonucuna varmışlardır.

Dini inançlar sebebiyle gebelik düşünmese bile tubal reanastomoz işlemini yaptırmak isteyen hastalar da olabilir. Bazı hastalar işlem sonrası başka korunma yöntemleri kullanarak gebelikten kaçınabilirler ve bu durum tubal reanastomoz sonrası gebelik oranlarını da etkileyebilir.

Tubal reanastomoz sonrası oluşan ektopik gebelikler ise en önde gelen korkulan komplikasyondur. Literatürde tubal rekonstrüktif cerrahi sonrası ektopik gebelik oranları \%1 ile \%19 arasında değişmektedir ${ }^{15-}$ 18. Van Seeters ve ark. yaptığı bir derlemede ektopik gebelik oranı \%4-8 oranında bulunmuştur ${ }^{13}$. Çalışmamızda hastalarımızın hiçbirinde ektopik gebelik oluşmamıştır. Bunun sebebi tuba uterinanın içerisinde kalan epidural kataterin tüpün daha düzgün bir biçimde iyileşmesine katkı sağlaması sebebiyle olabilir.

Literatürde tubal reanastomozun maliyetinin değerlendirildiği çalışmalar da mevcuttur. Messinger ve ark. yaptığı bir çalışmada 41 yaş altındaki kadınlarda her bir gebelik bașına tubal reanastomozun invitro fertilizasyon yöntemine göre daha uygun maliyetli olduğu sonucuna varılmıştır ${ }^{19}$. Çalışmamızdaki hastaların yaş ortalamasının $35,25 \pm 4,08$ olduğu ve literatürde de benzer yaşlara sahip kadınların vazgeçerek tekrar gebelik istediği de göz önüne alındığında, tüp ligasyonu dışında gebeliğe engel başka bir problemi olmayan hastalarda tubal reanastomoz maliyet etkin görülmektedir. Ayrıca bazı çalışmalarda invitro fertilizasyona klyasla tubal reanastomozda daha yüksek gebelik oranları da bildirilmiştir9.

Çalışmamızın yeni bir teknik olması ve bu teknik sonrası tüplerin açılma oranının literatürden yüksek olması güçlü yanı olarak gösterilebilir. Ancak çalışmamızın bazı kısıtlılıkları da mevcuttur. Retrospektif olması 
ve hasta sayısının az olması bunlara örnek verilebilir.

\section{SONUÇ}

Tubal sterilizasyon sonrası herhangi bir sebeple tekrar gebelik planlayan ve gebeliğe engel bașka bir problemi olmayan özellikle genç yaştaki kadınlar için tubal reanastomoz işlemi etkin bir yöntemdir. İnvitro fertilizasyon gibi yardımcı üreme tekniklerine göre ise maliyet etkin bir yöntem olması da avantaj sağlamaktadır ve bir alternatif olarak hastalara sunulmalıdır.

Etik Kurul Kararı: Helsinki bildirgesine göre çalışmaya dahil edilmiş olup katılımcılardan bilgilendirilmiş olur alınmıștır. Yerel etik kurul 2021/167 numarasıyla bu çalışmayı onaylamıştır.

Çıkar Çatışması Beyanı: Yazarlar çıkar çatışması olmadığını bildirmişlerdir.

Finansal Destek: Bu çalışma herhangi bir fon tarafından desteklenmemiștir.

Declaration of Conflicting Interests: The authors declare that they have no conflict of interest.

Financial Disclosure: No financial support was received.

\section{KAYNAKLAR}

1. Mosher WD, Jones J. Use of contraception in the United States: 1982-2008. Vital Health Stat 23. 2010; 29: 1-44.

2. Potter JE, Perpétuo IH, Berquó E, et al. Frustrated demand for postpartum female sterilization in Brazil. Contraception. 2003; 67: 385-90.

3. Platz-Christensen JJ, Tronstad SE, Johansson O, et al. Evaluation of regret after tubal sterilization. Int J Gynaecol Obstet. 1992; 38: 223-6.

4. Yapça ÖE, Gümüşburun N, Al RA, et al. Pregnancy Outcomes After Tubal Reanastomosis, 10-Year Experience at a Tertiary Center. JAREM. 2018; 8: 79-82.

5. Kavoussi SK, Kavoussi KM, Lebovic DI. Robotic-assisted tubal anastomosis with one-stitch technique. J Robot Surg. 2014; 8: 133-6.
6. Yavuz A, Akkurt MO, Yalçin Y, et al. Tubal Reanastomoz Sonrası Gebelik Sonuçları. Turkiye Klinikleri J Gynecol Obst. 2015; 25: 227-30.

7. Şentürk MB, Budak MŞ, Toğrul C, et al. Tubal Reanastomoz Yapılan Olguların Gebelik Oranları. Okmeydanı Tıp Dergisi. 2016; 32: 79-82.

8. Godin PA, Syrios K, Rege G, et al. Laparoscopic Reversal of Tubal Sterilization; A Retrospective Study Over 135 Cases. Front Surg. 2019; 5: 79.

9. Chua KH, Chan JK, Liu S, et al. Laparoscopic Tubal Reanastomosis or In Vitro Fertilisation in Previously Ligated Patients: A Comparison of Fertility Outcomes and Survey of Patient Attitudes. Ann Acad Med Singap. 2020; 49: 1805 .

10. Berger GS, Thorp Jr JM, Weaver MA. Effectiveness of bilateral tubotubal anastomosis in a large outpatient population. Hum Reprod. 2016; 31: 1120-5.

11. Deffieux X, Surroca MM, Faivre E, et al. Tubal anastomosis after tubal sterilization: a review. Arch Gynecol Obstet. 2011; 283: 1149-58.

12. Ai J, Zhang P, Jin L, et al. Fertility outcome analysis after modified laparoscopic microsurgical tubal anastomosis. Front Med. 2011; 5: 310-4.

13. van Seeters JA, Chua SJ, Mol BW, et al. Tubal anastomosis after previous sterilization: a systematic review. Hum Reprod Update. 2017; 23: 358-70.

14. Koteshwar S, Siddesh A. A study of tubal recanalization in era of ART (assisted reproduction technology). J Clin Diagn Res. 2016; 10: QC01-03.

15. Schippert C, Soergel P, Staboulidou I, et al. The risk of ectopic pregnancy following tubal reconstructive microsurgery and assisted reproductive technology procedures. Arch Gynecol Obstet. 2012; 285: 863-71.

16. Gomel V. Microsurgical reversal of female sterilization: a reappraisal. Fertil Steril. 1980; 33: 587-97.

17. Hirth R, Zbella E, Sanchez M, et al. Microtubal reanastomosis: success rates as compared to in vitro fertilization. J Reprod Med. 2010; 55: 161-5.

18. Cetin C, Cetin MT, Ürünsak IF. Unilateral laparoscopic tubal reversal versus IVF. J Laparoendosc Adv Surg Tech A. 2013; 23: 771-4.

19. Messinger LB, Alford CE, Csokmay JM, et al. Cost and efficacy comparison of in vitro fertilization and tubal anastomosis for women after tubal ligation. Fertil Steril. $2015 ; 104: 32-8$. 